\title{
THE EFFECTS OF TEACH BACK METHOD ON CAREGIVERS' STRAIN IN HANDLING PATIENTS WITH PROLONGED IMMOBILIZATION
}

\author{
Weizheng Zhang \\ Department of Interventional Operating Room, HeNan Cancer Hospital, China \\ Email: z874226398@163.com
}

Cite this article:

Weizheng Zhang (2021), The Effects of Teach Back Method on Caregivers' Strain in Handling Patients with Prolonged Immobilization. African Journal of Health, Nursing and Midwifery 4(6), 139-153. DOI: 10.52589/AJHNMIYNVJNMH.

\section{Manuscript History}

Received: 22 Nov 2021

Accepted: 21 Dec 2021

Published: 30 Dec 2021

Copyright $(\subset 2020$ The Author(s).

This is an Open Access article distributed under the terms of Creative Commons AttributionNonCommercial-NoDerivatives 4.0 International (CC BY-NC-ND

4.0 ), which permits anyone to share, use, reproduce and redistribute in any medium, provided the original author and source are credited.
ABSTRACT: Background: Caregivers' strain mainly comes from lack of relevant care knowledge and nursing skills. Traditional health education is just a one-way information transmission mode without evaluation and feedback. Objective: To help caregivers' memory, the researcher utilized a quasiexperimental design to measure the effectiveness of the teachback method on caregivers' strain in handling patients with prolonged immobilization. Method: A total of forty caregivers were averagely assigned into treatment (Teach-Back) and comparison group (traditional). Participant's Data Sheet, The Zarit Burden Interview and Teach Back Assessment Tool was used to gather data. Results: There was a significant difference in caregivers' strain before and after the Teach-Back Method in treatment $(p<0.001)$ and comparison group $(p<0.001)$. Likewise, a significant difference existed after the Teach-Back Method in the treatment group $(p<0.001)$. Conclusion: The Teach-Back Method is an effective intervention in reducing caregivers' strain in handling patients with prolonged immobilization.

KEYWORDS: Teach-Back Method, Caregivers, Caregivers' Strain, Prolonged Immobilization 


\section{INTRODUCTION}

Immobility is associated with the development of a series of complications, including pressure ulcer, deep vein thrombosis, pneumonia, and urinary tract infection. The complications of immobility could lead to diverse dangerous consequences which include increase morbidity, mortality, long hospitalization days, more hospital cost and global disease burden (Xu, 2018). In addition, every year, tens of thousands of elderly patients in China lose their ability to take care of themselves, which increases caregivers' strain (Wang, Zhou \& Lv, 2017). Stress injury is the most common complication of long-term bedridden patients, which can not only prolong the course of treatment but also increase the burden of caregivers (Li, Zhou \& Wang, 2018).

Although nurses play a leading role in preventing complications in bedridden patients, caregivers are the main implementers of some care. Not only do family caregivers need to provide basic care for the elderly in their daily lives, but care also needs to be provided to monitor patients' progress and prevent potential illnesses (Ajay, Kasthuri, Kiran \& Maihotra, 2017). Thus, long-term care has a greater influence on the health condition and quality of life among caregivers, including caregivers' physical health, but also negatively affects their mental health (Liu \& Tang, 2018). Caregivers are characterized by high work intensity, difficult work, long working hours, less financial resources, less social entertainment, and high psychological pressure. Stress occurs when their needs are not met (Huang, Wang \& Chen, 2016). Long-term care can bring physical and mental discomfort as well as economic pressure to the caregivers. Foreign studies have found that most caregivers lack relevant care knowledge, disease knowledge and nursing skills, and it is difficult for caregivers to provide high-quality care services, and they are in great need of nursing skills, rehabilitation and healthcare, predisposing them to caregivers' strain (Sabzwari, Badini, Fatmi, Jamali \& Shah, 2016).

Health education is one of the possible solutions to decrease the caregivers' strain. However, traditional health education is often based on simple indoctrination, which is a one-way information transmission mode without timely evaluation and feedback on patients' understanding and information mastery. According to Pan, Zhang, S., and Zhang, Z. R (2016), after receiving health education, some patients immediately forget 40 to 80 percent of the health information. In order to improve the effectiveness of health education, scholars at home and abroad have been committed to exploring new forms of health education and one of the new ways and gaining popularity is the Teach-Back Method.

The Teach-Back Method is to let the information providers express their understanding of educational information in their own language after carrying out health education. For the information that providers misunderstand or do not understand, the educators should emphasize it again (Pan et al., 2016). Teach-Back Method is considered to be a practical health education method for any population, especially for people lacking health literacy (Caplin \& Saunders, 2015; Porter et al., 2016). In addition, the Joint Commission, and the Health Care Improvement Institute of the United States (U.S.) Agency for Healthcare Research and Quality regarded Teach-Back as a comprehensive prevention approach.

The caregivers' strain in handing patients with prolonged immobilization mainly comes from a lack of relevant care knowledge, disease knowledge and nursing skills. The researcher believed that Teach-Back Method can quickly and comprehensively enhance the healthcare knowledge and skills of caregivers. Hence, this study has investigated the effects of the teachback method on caregivers' strain in handling patients with prolonged immobilization. 


\section{Theoretical Underpinning}

This study is based on Orem's Self-care Deficit theory by Dorothea Elizabeth Orem created in 1971. The theory's main components indicate that self-care is the behaviour created and adopted by individuals to ensure survival, maintain and promote health and well-being, which emphasizes that the ultimate goal of nursing is to restore and enhance the self-care ability of individuals and even the whole society (Orem, 1971).

The core of this theory is when an individual is unable to meet his or her self-care requisites, a self-care deficit occurs. It is the job of the registered nurse to determine these deficits and define a support modality. The theory helps enhance the quality of nursing care since nurses are allowed to express what they provide for patients and the reason why they do it (Younas \& Quennell, 2019). Nurses become agents to minimize deficits. The application of this theory is not only limited to individuals but also can be applied at all levels of family, group and society, which has strong operability and wide application value (Ke, 2018).

Patients with prolonged immobilization in this study, their care mainly relies on caregivers, which means caregivers become agents of patients with prolonged immobilization. As agents of care, the caregivers are responsible for minimizing complications in prolonged immobilization. Caregiver's ability to care appears to affect agency care requisites which may include demographic profile like age, sex, civil status, educational attainment, occupation, family monthly income and length of care a day. When the caregiver's self-care strength cannot meet the care needs, in other words, there is a large gap between the caregivers' self-care strength and the therapeutic self-care needs, which will have a bad impact on the bedridden patients and caregivers will also be under great pressure. This situation requires relevant professionals to provide corresponding measures to make up for the lack of self-protection strength. It is necessary to evaluate the caregivers in many aspects to determine whether caregivers have insufficient self-protective strength. Therefore, this study has used the TeachBack health education method as a nursing intervention to reduce caregivers' strain.

\section{METHODOLOGY}

This study utilized the quasi-experimental design, specifically the nonequivalent control group design with pretest-posttest control group design. Polit and Beck (2019) define nonequivalent control group design as the most frequently used quasi-experimental design that involves an experimental treatment, and two groups of subjects observe before and after its implementation.

In this study, the participants had their pretest in order to gather baseline data on their strain and to select eligible participants. The Teach-Back health education method was given to the treatment group and after that, this group also received an assessment as a part of the intervention from the researcher to evaluate if they understood the health information. However, the comparison group just received regular health education, but the content was the same in both groups. After the intervention, both groups were given a posttest to measure the effectiveness of the intervention.

The inclusion criteria are the following: (a) caregivers who have been taking care of patients with prolonged immobilization for more than 3 days, (b) the score of caregivers' strain is 
between 21 and 88, (c) have not attended any seminars or lectures about immobilization, (d) could read and speak the Chinese language, (e) no barriers to understanding, communication and expression, (f) show a willingness to participate in this study.

The study was conducted at the Henan Cancer Hospital, Zhengzhou City, China and ethical clearance was also obtained. The subjects involve forty (40) caregivers of patients with prolonged immobilization who are from different departments and buildings without any communication and do not know each other. Forty (40) caregivers who met the exclusion criteria with similar interventions were excluded. Also, the researcher did not select who were exposed to a similar intervention and any caregivers who had a similar intervention. Forty (40) caregivers were assigned into two groups in terms of the treatment group and comparison group. Therefore, there were twenty (20) caregivers assigned as the treatment group and the other twenty (20) caregivers were assigned as the comparison group.

After the intervention, caregivers of the two groups who were from different departments and buildings without any communication and not knowing about each other at all, and were willing to agree with the requirement from the researcher to never mention the content of health education to other caregivers in this study, to prevent contamination.

The following research instruments were used in the study:

- Participant's Data Sheet. This was originally drafted by the researcher and was the first part of the tool that was used to gather the demographic data of the participants like age, sex, civil status, educational attainment, family monthly income, occupation, and length of care in a day.

- The Zarit Burden Interview. The level of caregiver's strain was measured in this study using The Zarit Burden Interview. It was Zarit who first proposed an operational definition of caregiver burden and developed an assessment tool for feelings of caregivers' burden. The ZBI is now the most widely used technique used in North America and Europe for evaluating the strain experienced by family caregivers who take care of the communityresiding impaired elderly. It comprises 22 questions graded on a scale from 0 to 4 , according to the presence or intensity of an affirmative response, and measures the caregiver's health, psychological well-being, social life, finances, and the relationship between the caregiver and patient. The internal consistency ranged from 0.85 to 0.94 .

- Teach-Back Assessment Tool. An assessment tool which was self-made by the researcher to rate parameters as to the ability of the caregiver to teach back or repeat the health education taught by the nurse, which comprised of 24 items graded on a scale from 0 to 4 , respectively $0=$ cannot repeat, $1=20 \%$ of repetition, $2=50 \%$ of repetition, $3=80 \%$ of repetition and $4=100 \%$ of total repetition. The Teach-Back Tool was content validated by two experts and was not pilot tested and therefore, there is no claim of its reliability. 
The following steps were undertaken for the data gathering:

Phase I : Social Preparation: Prior to the initiation of the study, the researcher secured a letter regarding the ethical consideration and research approval from the Independent Ethics Committee of De La Salle Medical and Health Sciences Institute. The researcher also secured approval from Dr. Celso P. Pagatpatan, Dean of Graduate Studies in Medical and Health Sciences and Dr. Allely S. Reyes, the Program Director for validating the Teach-Back Assessment Tool.

Phase II: Data Gathering: The actual data gathering was further divided into four phases which include: Coordination Phase, the Facilitation Phase, the Application of the Intervention and the Post Intervention Phase.

- Coordination Phase

1. The researcher coordinated with the head of the nursing department regarding the nature and purpose of the study. The flow of the research was also coordinated with the concerned officials and personnel of the hospital.

2. The researcher then made a survey and a list of caregivers that were qualified to be participants in the study.

3. The qualified list of participants was forwarded to the head of the nursing department for reference and approval.

- Facilitation, Explanation of the Study and Pre-intervention Phase

This was where the researcher conducted her data gathering. Prior to the administration of the Teach-Back Method, a series of steps was undertaken in order to generate relevant data from the participants and determine their qualifications as participants in the study.

4. The researcher introduced herself and facilitated the explanation of the scope of the study to the participants through written informed consent.

5. When the participants agreed, the written informed consent, which is made by the researcher for the purpose of this study, was given to the participants to sign indicating that he or she was willing to participate in the study. Emphasis on withdrawal to participate in the study was likewise made.

6. After signing the written informed consent, this was followed by filling out the participant's datasheet for the determination of the participants' profile and the Zarit Burden Interview for pretest to select eligible participants as the baseline data.

7. The eligible participants were allocated to either the treatment or comparison group.

8. Once finished, the researcher prepared the materials needed for the intervention.

- Prior to Intervention 
Before the intervention, the research introduced herself and the objectives of the study in a five-minute introduction.

\section{Treatment Group}

- Application of Treatment

9. The intervention consisted of the following:

a. On week 1 of Monday in the morning, half-hour Teach-Back method health education based on the content of health education created by the researcher was given, which was conducted at the meeting room of the hospital. The content included the prevention measures of complications of prolonged immobilization and methods for reducing caregivers' strain, which was shown in Appendix K. Every caregiver was given one copy of the health education content so that they could read it when they were free to ensure that in case, they forgot the health information was available through prepared handouts.

b. After health education, the researcher assessed them one by one on their understanding of the health education content using the Teach-Back Assessment Tool. Twenty (20) caregivers were assessed individually using the Teach-Back assessment on the following days from Tuesday to Saturday. The researcher assessed four (4) respondents individually a day particularly two (2) respondents in the morning and another two (2) respondents in the afternoon from Tuesday to Saturday. The researcher had unlimited time for clarification and assessment of the health information to determine their understanding and their ability to teach back. The assessment was not ended until their understanding was totally correct.

10. On week 2, the above activity was followed again. The content of health education and the assessment were repeated.

- Post Intervention

After assessing the respondents of the second week, the researcher counted three (3) days for every caregiver who was assessed by the researcher through the Teach-Back Assessment tool, and then that was the time to let caregivers fill out ZBI. Letter $\mathrm{R}$ in the table stand for respondent. The detail process was conducted as follows: 
African Journal of Health, Nursing and Midwifery

ISSN: 2689-9418

Volume 4, Issue 6, 2021 (pp. 139-153)

www.abjournals.org

Table 1: The Detailed Process of the Study

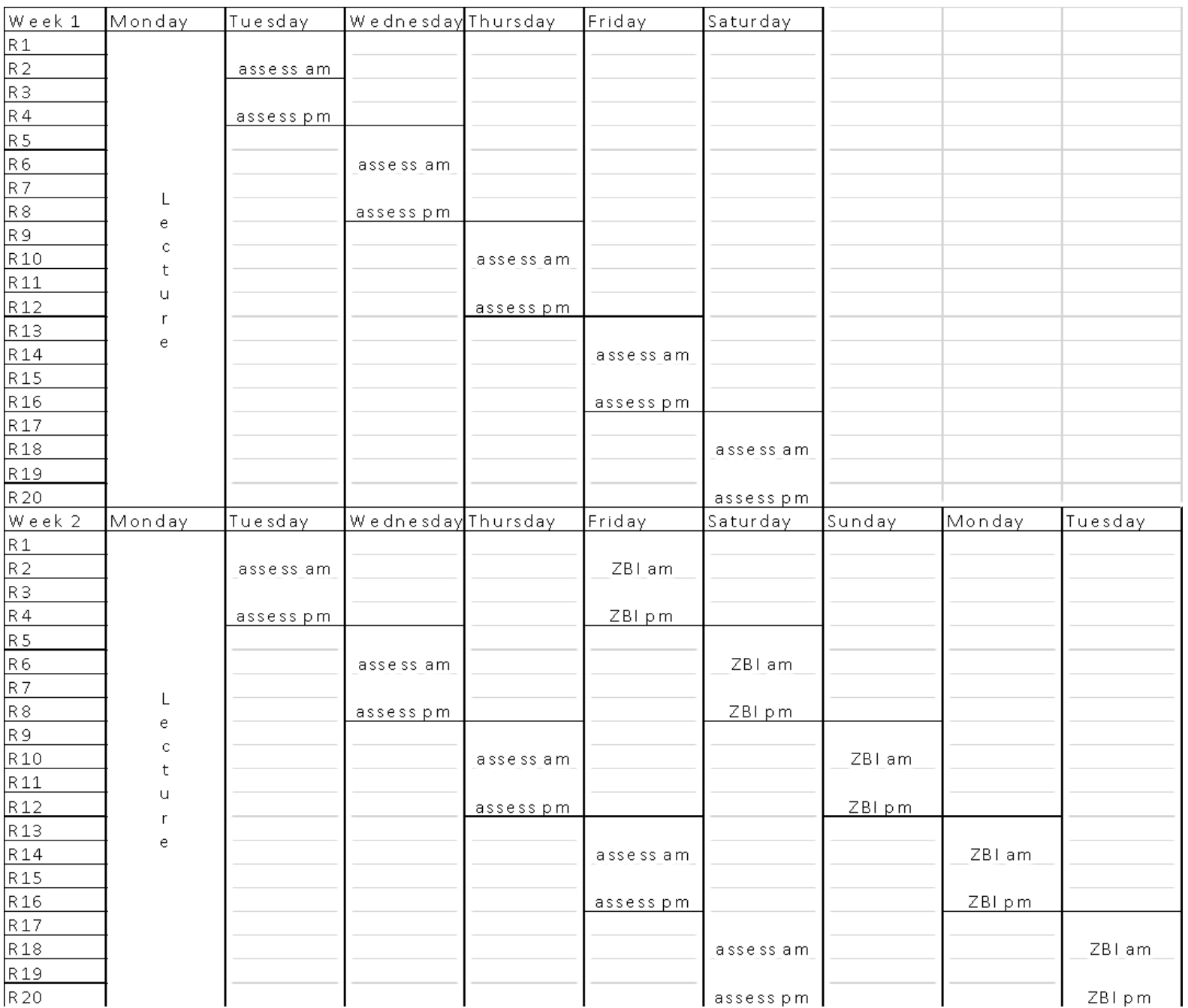

\section{Comparison Group}

All the processes from Step 1 to 10 except Step 9 that was the application of the Teach-Back Method was applied to the participants in the comparison group.

The following statistical treatments were used to answer the specific problems and to test the hypothesis of the research. (a) Percentage Distribution, (b) Frequency Distribution (c) Mean, (d) Fisher's Exact Test, (e) Chi-square, (f) Paired t-test and (g) Independent t-test 
a. Percentage Distribution-This is a statistic that represents the proportion of a sub-group, expressed as a percentage ranging from 0 to 100 . A percentage distribution is the number of parts per hundred that a certain portion of the whole represents (Nieswiadomy, 2018). In this study, the percentage distribution was used to determine the profile of the participants in terms of age, sex, civil status, educational attainment, family monthly income, length of care in a day.

b. Frequency Distribution-This is a systematic arrangement of values that states a count or percentage of how many times each value occurred (Polit \& Beck, 2019). This determines the proportion of a part or a whole such as a given number of participants in relation to the sample population. In this study, the frequency distribution was used to determine the profile of the participants in terms of age, sex, civil status, educational attainment, family monthly income, length of care in a day.

c. Mean- The mean, sometimes abbreviated as $M$, is the average sum of a set of values found by adding all values and dividing by the total number of values (Nieswiadomy, 2018). In this study, the mean was used to determine the level of caregivers' strain before and after intervention between treatment and comparison group.

d. Fisher's Exact Test- This is a statistical significance test used in the analysis of contingency tables. Especially when more than $20 \%$ of cells have expected frequencies $<5$, we need to use Fisher's exact test because applying the approximation method is inadequate (HaeYoung Kim, 2017). In this study, Fisher's Exact Test was used to analyze variables age, civil status, educational attainment, monthly family income, and length of care.

e. Chi-square-It is a statistical hypothesis test that is valid to perform when the test statistic is chi-squared distributed under the null hypothesis. It is used to compare the distribution of a categorical variable in a sample or a group with the distribution in another one (Hae-Young Kim, 2017). In this study, Chisquare was used to analyze group differences on sex since the variables violate the assumption of Chi-square that the value of the cell expected should be 5 or more in at least $80 \%$ of the cells, and no cell should have an expected of less than one.

f. Paired t-test - A paired sample t-test is used to compare the same subjects before and after treatment. Pairing the subjects are controlled in similar conditions and then giving them two different treatments to observe whether there are differences in the two treatments (Kim and Mallory, 2015). In this study, it was used to find significant differences in the level of caregivers' strain before and after the Teach-Back method in the treatment and comparison groups.

g. Independent t-test- A common research statistic is the comparison of two groups of subjects with regard to the dependent variables. The appropriate analytic procedure for testing the statistical significance of the difference between the means of two groups is the parametric test known as the t-test (Polit \& Beck 2019). Thus, this statistical treatment was used to compare the differences in the level of the strain of caregivers of patients between the treatment and comparison groups before and after the Teach-Back Method. 
RESULTS

Table 2: Profile of the Participants in the Control and Treatment Groups

\begin{tabular}{|c|c|c|c|c|c|c|}
\hline \multirow[t]{2}{*}{ Profile } & \multicolumn{2}{|c|}{$\begin{array}{l}\text { Treatment } \\
\text { Group }\end{array}$} & \multicolumn{2}{|c|}{$\begin{array}{c}\text { Comparison } \\
\text { Group }\end{array}$} & \multirow{2}{*}{$\begin{array}{c}\text { p- } \\
\text { Value }\end{array}$} & \multirow[t]{2}{*}{ Interpretation } \\
\hline & $\mathrm{f}$ & $\%$ & $\mathrm{f}$ & $\%$ & & \\
\hline \multicolumn{7}{|l|}{ Age } \\
\hline $18-35$ & 10 & $50 \%$ & 13 & $65 \%$ & \multirow{3}{*}{0.663} & \multirow{3}{*}{ Not Significant } \\
\hline $36-50$ & 7 & $35 \%$ & 5 & $25 \%$ & & \\
\hline$\geq 51$ & 3 & $15 \%$ & 2 & $10 \%$ & & \\
\hline \multicolumn{7}{|l|}{ Sex } \\
\hline Male & 9 & $45 \%$ & 9 & $45 \%$ & \multirow[t]{2}{*}{1.000} & \multirow[t]{2}{*}{ Not Significant } \\
\hline Female & 11 & $55 \%$ & 11 & $55 \%$ & & \\
\hline \multicolumn{7}{|l|}{ Civil Status } \\
\hline Single & 8 & $40 \%$ & 11 & $55 \%$ & \multirow{4}{*}{0.538} & \multirow{4}{*}{ Not Significant } \\
\hline Married & 8 & $40 \%$ & 8 & $40 \%$ & & \\
\hline Divorced & 3 & $15 \%$ & 1 & $5 \%$ & & \\
\hline Widowed & 1 & $5 \%$ & 0 & $0 \%$ & & \\
\hline \multirow{2}{*}{\multicolumn{7}{|c|}{$\begin{array}{c}\text { Educational } \\
\text { Attainment }\end{array}$}} \\
\hline & & & & & & \\
\hline Primary & 9 & $45 \%$ & 16 & $80 \%$ & \multirow{4}{*}{0.118} & \multirow{4}{*}{ Not Significant } \\
\hline Junior & 5 & $25 \%$ & 1 & $5 \%$ & & \\
\hline Senior & 4 & $20 \%$ & 2 & $10 \%$ & & \\
\hline$\geq$ University & 2 & $10 \%$ & 1 & $5 \%$ & & \\
\hline \multicolumn{7}{|l|}{ Occupation } \\
\hline Farmer & 7 & $35 \%$ & 3 & $15 \%$ & \multirow{4}{*}{0.441} & \multirow{4}{*}{ Not Significant } \\
\hline Staff & 3 & $15 \%$ & 2 & $10 \%$ & & \\
\hline Teacher & 3 & $15 \%$ & 4 & $20 \%$ & & \\
\hline Others & 7 & $35 \%$ & 11 & $55 \%$ & & \\
\hline \multicolumn{7}{|c|}{$\begin{array}{c}\text { Monthly Family } \\
\text { Income }\end{array}$} \\
\hline Below 1000 & 1 & $5 \%$ & 1 & $5 \%$ & \multirow{4}{*}{0.759} & \multirow{4}{*}{ Not Significant } \\
\hline $1000-2999$ & 3 & $15 \%$ & 1 & $5 \%$ & & \\
\hline $3000-4999$ & 7 & $35 \%$ & 6 & $30 \%$ & & \\
\hline$\geq 5000$ & 9 & $45 \%$ & 12 & $60 \%$ & & \\
\hline \multicolumn{7}{|c|}{$\begin{array}{l}\text { Length of Care } \\
\text { in A Day }\end{array}$} \\
\hline$\leq 1$ hour & 6 & $30 \%$ & 5 & $25 \%$ & \multirow{4}{*}{0.513} & \multirow{4}{*}{ Not Significant } \\
\hline 1 to 2 hours & 7 & $35 \%$ & 5 & $25 \%$ & & \\
\hline 3 to 4 hours & 5 & $25 \%$ & 4 & $20 \%$ & & \\
\hline$\geq 4$ hours & 2 & $10 \%$ & 6 & $30 \%$ & & \\
\hline
\end{tabular}


Table 3: The Strain among the Participants Between the Comparison and Treatment Groups Before and After Teach-Back Health Education Method

\begin{tabular}{ccccccccc}
\hline \multirow{2}{*}{ Intervention } & \multicolumn{3}{c}{ Treatment group } & & \multicolumn{3}{c}{ Comparison Group } \\
\cline { 2 - 4 } Pre-Intervention & 65.90 & 8.23 & Severe & & 65.95 & 13.33 & Severe \\
Post-Intervention & 39.95 & 8.48 & $\begin{array}{c}\text { Mild to } \\
\text { Moderate }\end{array}$ & & 52.40 & 10.50 & $\begin{array}{c}\text { Moderate to } \\
\text { Severe }\end{array}$ \\
\hline
\end{tabular}

Legend:

61.00-88.00: severe burden

41.00-60.99: moderate to severe burden

21.00-40.99: mild to moderate burden

0.00-20.99: little or no burden

Table 4: Comparison of the Caregivers' Strain between the Treatment and Comparison Groups Before and After Teach-Back Health Education Method

\begin{tabular}{|c|c|c|c|c|c|c|c|}
\hline \multirow{2}{*}{ Group } & \multicolumn{2}{|c|}{$\begin{array}{c}\text { Pre- } \\
\text { Intervention }\end{array}$} & \multicolumn{2}{|c|}{ Post-Intervention } & \multirow{2}{*}{$\begin{array}{c}\text { Paire } \\
\text { d } t- \\
\text { ratio }\end{array}$} & \multirow{2}{*}{ P-value } & \multirow{2}{*}{$\begin{array}{c}\text { Interpretatio } \\
\mathbf{n}\end{array}$} \\
\hline & Mean & SD & Mean & $\mathrm{SD}$ & & & \\
\hline Treatment & 65.90 & 8.23 & 39.95 & 8.48 & 22.601 & $<0.001$ & S \\
\hline Comparison & 65.95 & 13.33 & 52.40 & 10.50 & 11.172 & $<0.001$ & S \\
\hline
\end{tabular}

$\mathrm{S}$ - Significant at 0.05 level using 19 degrees of freedom

Table 5: Comparison of the Mean Differences between the Treatment and Comparison Groups

\begin{tabular}{cccccc}
\hline Group & n & Mean Diff. & SD & Computed $t$-ratio & P-value \\
\hline Treatment & 20 & 25.95 & 5.13 & & \\
Comparison & 20 & 13.55 & 5.42 & 7.425 & $<0.001$ \\
\hline S - Significant at 0.05 level using 38 degrees of freedom
\end{tabular}


Table 6: Comparison of the caregivers' Strain Between the Treatment and Comparison Groups Before and After Teach-Back Health Education Method

NS - Not Significant at 0.05 level using 38 degrees of freedom

$\mathrm{S}$ - Significant at 0.05 level using 38 degrees of freedom

\begin{tabular}{|c|c|c|c|c|c|c|c|c|}
\hline \multirow{2}{*}{ Intervention } & \multicolumn{2}{|c|}{ Treatment } & \multicolumn{2}{|c|}{ Comparison } & \multirow[t]{2}{*}{$\begin{array}{c}\text { Mean } \\
\text { Diff. }\end{array}$} & \multirow[t]{2}{*}{$\begin{array}{c}t- \\
\text { ratio }\end{array}$} & \multirow[t]{2}{*}{$\begin{array}{c}P- \\
\text { value }\end{array}$} & \multirow[t]{2}{*}{ Interpretation } \\
\hline & $\begin{array}{c}\text { Mea } \\
\mathrm{n}\end{array}$ & SD & Mean & SD & & & & \\
\hline Pre & $\begin{array}{c}65.9 \\
0\end{array}$ & $\begin{array}{c}8.2 \\
3\end{array}$ & 65.95 & $\begin{array}{c}13.3 \\
3\end{array}$ & 0.05 & 0.014 & 0.989 & NS \\
\hline Post & $\begin{array}{c}39.9 \\
5\end{array}$ & $\begin{array}{c}8.4 \\
8\end{array}$ & 52.40 & $\begin{array}{c}10.5 \\
0\end{array}$ & 12.45 & 4.126 & $<0.001$ & $\mathrm{~S}$ \\
\hline
\end{tabular}

From the presented data, the following were deduced and depicted in the order of the questions stated at the beginning of the study:

1. There is equal distribution of participants in terms of sex. The majority of the participants belong to the age group of 18 to 35 years old, single, finished primary education, with a monthly family income of more than 5,000 RMB, with other work than farmer and teacher and with one to two hours length of care in a day. There was no significant difference between the treatment and comparison groups in terms of their age $(p=0.663)$, sex $(\mathrm{p}=1.000)$, civil status $(\mathrm{p}=0.538)$, educational attainment $(\mathrm{p}=0.118)$, occupation $(\mathrm{p}=0.441)$, monthly family income $(\mathrm{p}=0.759)$, and length of care in a day $(\mathrm{p}=0.513)$.

2. Both participants from the treatment $(M=65.90, S=8.23)$ and comparison $(M=65.95$, $\mathrm{SD}=13.33$ ) groups had severe strain prior to the implementation of the Teach-Back health education method. The participants from the treatment group had mild to moderate strain $(\mathrm{M}=39.95, \mathrm{SD}=8.48)$ after the Teach-Back health education method while participants from the comparison group had moderate to severe strain $(\mathrm{M}=52.40, \mathrm{SD}=10.50)$.

3. There was a significant difference in the level of caregivers' strain before and after the Teach-Back health education in the treatment group, $(\mathrm{M}=25.95)$ and comparison group, $t(19)=11.172, p<0.001$. The mean difference of the treatment group $(M=25.95)$ was significantly higher than the mean difference of the comparison group $(\mathrm{M}=5.42), \mathrm{t}(38)=$ $7.425, \mathrm{p}<0.001$.

4. There was no significant difference in the caregivers' strain between the treatment and comparison groups before the intervention, $\mathrm{t}(38)=0.014, \mathrm{p}=989$. A significant difference existed after the implementation of the Teach-Back health education in the treatment group as compared to the comparison group, $\mathrm{t}(38)=4.126, \mathrm{p}<0.001$. 


\section{DISCUSSION}

Findings of this study showed that:

In terms of age, the majority of the participants are 18 to 35 years old, suggesting that they belong to the young adult population. This further suggests that caregivers who belong to this population are part of the workforce and may be financially burdened considering that caring for an immobilized patient prevents them from working in companies or organizations that may provide them with a better salary and contribute to the economy of the country.

In terms of sex, most of the participants are female and believe that caregiving is relegated to the female population who may get stressed from taking care of an immobilized patient for such a long time. This further suggests that the caregivers who belong to this population is part of the care resources especially in China and may have care techniques or methods of reducing the burden they currently have.

In terms of civil status, the majority of the participants are single, further suggesting that caregivers who belong to the single population are more likely to be stressed than the married population, which may contribute to less assistance in taking care of an immobilized patient from family members such as spouse or children.

In terms of educational attainment, the majority of the participants' education attainment is university or above. In the consideration of the single adult population of the caregivers, most of them have relatively higher education attainment showing that to some degree high level of educational attainment may have something to do with burden reduction when taking care of an immobilized patient. Considering that this population is part of the working group, the burden may also be related to the possible financial problem.

In terms of occupation, most of the participants' have different occupations such as students, businessmen, while others have no job, compared to farmers, teachers and staff, which further may suggest that their job may not allow the caregivers to have enough or flexible time to take care of their patients. This is also possibly related to where their burden originally has generated.

In terms of family monthly income, the majority of the participants' family monthly income is above 5000RMB, suggesting that the income of this population is not that low, which further illustrated that the cost of taking care of an immobilized patient is quite expensive, no matter how much the family monthly income is. Again, the strain of caregivers is well explained by this financial issue.

In terms of length of care in a day, most of the participants' care time in a day was 1 to 2 hours. In consideration of the caregivers work for the population, it is obvious that the patients cannot be taken care of by the caregivers from the short time they spend taking care of an immobilized patient, but also probably generates from not knowing how to provide a high quality of care within a limited time.

There was a significant difference in the comparison of the mean differences between the treatment and comparison groups. According to the mean differences of the two groups, caregivers' strain of treatment group was less than that of the comparison group, which indicates that the Teach-Back method of health education is a more efficient way than regular health education in reducing caregivers' strain. 


\section{IMPLICATIONS}

Based on the conclusions of the study, the following are recommended:

1. Health education based on the Teach-Back method is recommended as a very significant alternative intervention for helping caregivers remember the content of education as well as a tool in recalling the information given by the health education providers so that the caregivers will take more positive actions to improve their situation in taking care of their patients. This way, the level of strain will be reduced, and better care is given to their patients.

2. In consideration of the effectiveness of the Teach-Back method, the scope of its utilization should be expanded to all kinds of educational situations like teaching caregivers to reduce stress, guiding patients to do self-care at home, and facilitating patients to pay attention to the risk factors of their diseases.

3. It is recommended that the Teach-Back method be used as a promising alternative health education modality that could enhance the nursing student's basic knowledge of the care of caregivers.

4. Practicing nurses in different fields can utilize the Teach-Back method in teaching their patients and families about their disease conditions since health education is an important domain of nursing.

5. Nursing administrators should utilize and conduct more research to produce more evidence on the effectiveness of the Teach-Back method of health education as an effective intervention to improve caregivers' knowledge and reduce caregivers' burden. The applicability of the Teach-Back method on caregivers' strain is a possible alternative intervention in facilitating health education knowledge and improving caring skills for patients with prolonged immobilization.

\section{CONCLUSION}

Based on the findings generated by the study, the following conclusions were drawn:

1. There is equal distribution of participants in terms of sex. The majority of the participants belong to age group 18 to 35 years old, single, finished primary education, with monthly family income more than 5,000 RMB, with other work than farmer and teacher and with one to two hours length of care in a day. There was no significant difference between the treatment and comparison groups in terms of their age, sex, civil status, educational attainment, occupation, monthly family income, and length of care in a day.

2. The participants from the treatment group had severe strain prior to intervention and mild to moderate strain after Teach-Back health education. The participants from the comparison group had severe strain during pretest and moderate to severe strain during posttest. 
3. Significant reduction in the caregivers' strain was observed in the treatment group as compared to the comparison group.

4. Teach-Back health education method is an effective intervention in reducing the caregivers' strain in handling patients with prolonged immobilization.

\section{Future Research}

Future research may be conducted on the same topic utilizing other variables not included in this study or replicate this study using a different design like the true experimental design to consider other chronic conditions and other significant nursing topics.

\section{REFERENCES}

Ajay, S., Kasthuri, A., Kiran, P., \& Malhotra, R. (2017). Association of impairments of older persons with caregiver burden among family caregivers: Findings from rural South India. Archives of gerontology and geriatrics, 68, 143-148.

Caplin, M., \& Saunders, T. (2015). Utilizing teach back to reinforce patient education: a stepby-step approach. OrthopNurs, 34 (6), 365-368.

Huang, C.X., Wang, J., \& Chen, J. (2016). Characteristic needs and support policies for longterm family caregivers -- a case study of disabled elderly caregivers in Shanghai. Shanghai urban management, (5), 70-76.

Ke, Y.H. (2018). Application of Teach-Back Method for cognition and behaviours of pressure ulcer risk patient-oriented main caregivers.

Kim, M \& Mallory, C. (2015). Statistics for evidence-based practice in nursing. Wall Street, Jone \& Bartlett Learning.

Li, Y.N., Zhou, K.Y., \& Wang, Z.F. (2018). Evaluation of the effect of family nursing intervention on the prevention of stress injury in elderly patients with long-term bed rest after discharge of cerebral apoplexy. Chinese Medical Guide, 16(5), 232-233.

Liu, L.Z., Tang, F.P., Zhao, R., Luo, J.T., \& Cheng, L. (2018). Pressure and countermeasures of domestic and foreign elderly family caregivers. Chinese General Nursing, 6(15), 1811-1813.

Nieswiadomy, R.M.,(2018). Foundation of Nursing. Retrieved from https://books.google.com.ph/books?id=Pb0uAAAAQBAJ\&dq=(Nieswiadomy $+2015 \&$ h $1=$ en\&sa $=$ X\&ved=0ahUKEwihzPitrazkAhWPZt4KHdIoACUQ6AEINzAC.

Orem, D.E. (1971). Nursing: Concepts of practice. New York: McGraw-Hill.

Pan, C.L., Zhang, S., \& Zhang, Z.R. (2016). Application status of feedback method in nursing education. Journal of Nursing, 32 (14),110-112.

Polit, D.F., \& Beck, C.T. (2019). Resource manual for nursing research. Generating and assessing evidence for nursing practice (10th Ed.)

Porter, K., Chen, Y., \& Estabrooks, P., Noel, L., Bailey, A., \& Zoellner, J. (2016). Using teach-back to understand participant behavioural self-monitoring skills across health literacy level and behavioural condition. J nutrEducBehav, 48 (1), 20-26.

Sabzwari, S., Badini, M. A., Fatmi, Z., Jamali, T., \& Shah, S. (2016). Burden and associated factors for caregivers of the elderly in a developing country. EMHJ-Eastern Mediterranean Health Journal, 22(6), 394-403. 
Wang, W., Zhou, G.L., \& Lv, C.Y. (2017). Study on evidence-based nursing to prevent pressure ulcers in long-term bedridden elderly patients in cardiovascular medicine. Chinese Journal of Geriatric Care, 15(5), 93-94.

$\mathrm{Xu}$, W.X. (2018). Nursing management analysis of common complications in bedridden patients. China Academic Journal, 40(5), 381-382.

Younas, A., \& Quennell, S. (2019). Usefulness of nursing theory-guided practises an integrative review. Scandinavian journal of caring sciences, 33(3), 540-555. 